\title{
TOLERÂNCIA DO FEIJÃO-CAUPI AO HERBICIDA OXADIAZON ${ }^{1}$
}

\author{
José Roberto Antoniol Fontes², José Ricardo Pupo Gonçalves², Ronaldo Ribeiro de Morais²
}

\section{ABSTRACT}

\section{COWPEA TOLERANCE TO OXADIAZON}

The use of herbicides for weed control in cowpea [Vigna unguiculata (L.) Walp.] can result in highly effective control and lower production costs, if compared to mechanical control, especially weeding. However, not many studies were conducted in order to evaluate crop tolerance to herbicides. The objectives of this study were to evaluate cowpea tolerance, BRS Guariba cultivar, to the oxadiazon herbicide, applied in pre-emergence, at $200 \mathrm{~g}, 400 \mathrm{~g}, 600 \mathrm{~g}, 800 \mathrm{~g}$, and 1,000 g of active ingredient (a.i.) ha ${ }^{-1}$, and weed control effectiveness. The weeds identified were Cleome affinis, Commenlina benghalensis, Cyperus rotundus, and Euphorbia heterophylla. The cultivar BRS Guariba was very tolerant to all doses tested, and the weed control level was good. Grain yields obtained with doses above $600 \mathrm{~g}_{\text {a.i. }}$ ha $^{-1}$ were excellent, comparable to weeding performance during the critical period of weed competition, between 20 and 40 days after seedling emergence $\left(1,561 \mathrm{~kg} \mathrm{ha}^{-1}\right)$. The negative interference of weeds, throughout the cowpea life cycle, decreased yield by $59 \%$.

KEY-WORDS: Vigna unguiculata; chemical weed control; floristic inventory.

\section{INTRODUÇÃO}

O feijão-caupi (Vigna unguiculata) é uma das principais culturas alimentares nas regiões Norte e Nordeste do Brasil, que concentram a maior área cultivada e produção desta leguminosa. A produtividade, nestas regiões, é de cerca de $300 \mathrm{~kg} \mathrm{ha}^{-1}$ (Medeiros et al. 2008), não muito diferente daquela obtida no continente africano, maior região produtora, onde se registra produtividade média de $380 \mathrm{~kg} \mathrm{ha}^{-1}$ (Ishaya et al. 2008). Segundo Silva et al. (2000) e Ishaya et al. (2008), dentre os fatores que interferem, negativamente, na cultura, o manejo inadequado das plantas daninhas que ocorrem nas áreas de cultivo contribui para a redução de produtividade. Além

\section{RESUMO}

O uso de herbicidas, para controle de plantas daninhas na cultura do feijão-caupi [Vigna unguiculata (L.) Walp.], pode resultar em elevada eficácia de controle e menores custos de produção, quando comparados ao controle mecânico, principalmente capinas. Entretanto, são escassos os trabalhos de avaliação da tolerância desta cultura a herbicidas. Os objetivos deste trabalho foram avaliar a tolerância do feijão-caupi, variedade BRS Guariba, ao herbicida oxadiazon, aplicado em pré-emergência, com doses de 200 g, 400 g, 600 g, 800 g e 1.000 g de ingrediente ativo (i.a.) ha ${ }^{-1}$, e a eficácia de controle de plantas daninhas. As plantas daninhas identificadas na área experimental foram Cleome affinis, Commelna benghalensis, Cyperus rotundus e Euphorbia heterophylla. As plantas da variedade foram muito tolerantes a todas as doses testadas e o nível de controle de plantas daninhas foi satisfatório. As produtividades de grãos obtidas com doses acima de $600 \mathrm{~g}_{\text {i.a. }}$ ha $^{-1}$ foi excelente, comparável à obtida com a realização de duas capinas, durante o período crítico de competição de plantas daninhas com a cultura, entre 20 e 40 dias após a emergência das plântulas $\left(1.561 \mathrm{~kg} \mathrm{ha}^{-1}\right)$. A interferência negativa de plantas daninhas, durante todo o ciclo de vida da cultura, reduziu a produtividade de grãos em 59\%.

PALAVRAS-CHAVE: Vigna unguiculata; controle químico de planta daninha; levantamento florístico.

disso, algumas espécies de plantas daninhas servem como hospedeiros alternativos de doenças que atacam o feijão-caupi, como ocorre com a guanxuma (Sida rhombifolia), malva-sedosa (Waltheria indica), mussambê (Cleome affinis) e mela-bode (Herissantia crispa) (Assunção et al. 2006).

Nesse contexto, o uso de herbicidas, como um dos componentes de programas de manejo integrado de plantas daninhas, na cultura do feijão-caupi, permite elevada eficácia de controle, com redução de custos de produção. Entretanto, dois aspectos devem ser considerados, no que se refere ao emprego de herbicidas, nessa cultura: a inexistência de herbicidas registrados no Brasil, para controle de plantas daninhas, o que impede recomenda- 
ções; e a falta de conhecimento sobre a tolerância das muitas variedades aos herbicidas que podem ser utilizados na cultura (Harrison \& Fery 1993). Estes autores constataram grande variabilidade na tolerância de genótipos de feijão-caupi ao herbicida bentazon, utilizado para controle de plantas daninhas dicotiledôneas. Verificaram, ainda, que os genótipos mais suscetíveis foram mortos, ou muito afetados, com aplicações de $2.000 \mathrm{~g}$ i.a. ha $^{-1}$, enquanto os mais tolerantes resistiram à dose de $16.000 \mathrm{~g}_{\text {i.a. }} \mathrm{ha}^{-1}$. Silva et al. (2000) avaliaram a tolerância do feijão-caupi, variedade USA, aos herbicidas flumetsulan $\left(120 \mathrm{~g}_{\text {i.a. }} \mathrm{ha}^{-1}\right)$, oxyfluorfen $\left(480 \mathrm{~g}_{\text {i.a. }} \mathrm{ha}^{-1}\right)$, sulfentrazone $\left(600 \mathrm{~g}_{\text {i.a. }}\right.$ ha $\left.^{-1}\right)$, trifluralin $\left(720 \mathrm{~g}_{\text {i.a. }} \mathrm{ha}^{-1}\right)$, aciflurfen-sódio + bentazon $\left(160+600 \mathrm{~g}_{\text {i.a. }} \mathrm{ha}^{-1}\right)$, chlorimuron-ethyl (17 $\left.\mathrm{g}_{\text {i.a. }} \mathrm{ha}^{-1}\right)$, halosulfuron $\left(112 \mathrm{~g}_{\text {i.a. }} \mathrm{ha}^{-1}\right)$ e sethoxydim $\left(230 \mathrm{~kg}_{\text {i.a. }} \mathrm{ha}^{-1}\right)$, e verificaram que as plantas da cultura não foram afetadas por estes herbicidas. Silva et al. (2003) constataram que os herbicidas fenoxaprop-p-ethyl $\left(40 \mathrm{~g}_{\text {i.a. }}\right.$ ha $^{-1}, 80 \mathrm{~g}_{\text {i.a. }}$ ha $^{-1}$ e $120 \mathrm{~g}_{\text {i.a. }}$ ha $\left.^{-1}\right)$ e imazamox $\left(21 \mathrm{~g}_{\text {i.a. }}\right.$ ha $^{-1}, 42 \mathrm{~g}_{\text {i.a. }}$ ha $^{-1}$ e $63 \mathrm{~g}_{\text {i.a. }}$ ha $\left.^{-1}\right)$, aplicados em pós-emergência, foram eficazes no controle de plantas daninhas e não causaram injúrias às plantas da variedade EPACE-10, sobretudo quando associados aos herbicidas glyphosate e paraquat, usados como dessecantes, em sistema de plantio direto. Ishaya et al. (2008), na Nigéria, verificaram que a mistura dos herbicidas metolachlor + prometryn $(1.250+$ $800 \mathrm{~g}_{\text {i.a. }}$ ha $\left.^{-1}\right)$, aplicada em pré-emergência, promoveu excelente controle de plantas daninhas e não afetou, negativamente, o crescimento e a produtividade da variedade SAMPEA-7. Oliveira \& Silva (2008) avaliaram a tolerância das variedades de feijão-caupi Manteiguinha, Fígado-de-boi-vinagrão e Fígado-degalinha ao herbicida fomesafen $\left(200 \mathrm{~g}_{\text {i.a. }}\right.$ ha $\left.^{-1}\right)$, aplicado em pós-emergência, e constataram que apenas a última variedade não foi afetada pelo herbicida.

Considerando-se que a tolerância das variedades de feijão-caupi a herbicidas seja pouco avaliada, objetivou-se, neste trabalho, caracterizar a seletividade do herbicida oxadiazon, aplicado em préemergência ao feijão-caupi, variedade BRS Guariba, e estimar a eficácia de controle de plantas daninhas proporcionada por este herbicida.

\section{MATERIAL E MÉTODOS}

O experimento foi conduzido no Campo Experimental do Caldeirão, pertencente à Embrapa
Amazônia Ocidental $\left(03^{\circ} 15^{\prime} 17^{\prime}\right.$ 'S, 60¹3'34”'W e altitude de $52 \mathrm{~m}$ ), localizado no município de Iranduba (AM). O solo do local foi classificado como Argissolo vermelho-amarelo, com horizonte A antrópico (Terra Preta do Índio), de textura franco-argilo-arenosa, cujas características químicas mais importantes foram: $\mathrm{pH}$ em água $(1: 2,5): 5,32 ; \mathrm{P}: 152 \mathrm{mg} \mathrm{dm}^{-3}$; Ca: 6,21 $\mathrm{cmol}_{\mathrm{c}} \mathrm{dm}^{-3} ; \mathrm{Mg}: 2,65 \mathrm{cmol}_{\mathrm{c}} \mathrm{dm}^{-3}$; $\mathrm{K}: 44 \mathrm{mg} \mathrm{dm}^{-3} ; \mathrm{H}+\mathrm{Al}: 3,51 \mathrm{cmol}_{\mathrm{c}} \mathrm{dm}^{-3}$; matéria orgânica: 65,13 dag $\mathrm{kg}^{-1}$; CTC total: $13,31 \mathrm{cmol}_{\mathrm{c}} \mathrm{dm}^{-3}$; saturação por bases: $66,2 \%$; e saturação por alumínio: $1,01 \%$.

Em 23/04/2008, foi realizado levantamento florístico de plantas daninhas, para caracterizar a comunidade daninha presente na área experimental, adotando-se, para isto, o método do quadrado inventário (Braun-Blanquet 1979), lançando-se, aleatoriamente, 20 vezes, uma armação vazada de madeira de $0,5 \mathrm{~m}$ de lado. As plantas daninhas contidas pela armação foram identificadas por espécie e contadas, sendo calculada a frequência relativa, densidade relativa, abundância relativa e índice de importância relativa (Mueller-Dumbois \& Ellemberg 1974).

Para o preparo do solo, realizado em 24/04/2008, foram utilizados arado e grade de discos. O experimento foi instalado no delineamento em blocos casualizados, com quatro repetições. A semeadura da variedade BRS Guariba, de porte ereto, foi realizada manualmente, no dia 25/04/2008, em profundidade de $3 \mathrm{~cm}$, no espaçamento de $0,5 \mathrm{~m}$ entre fileiras e $0,3 \mathrm{~m}$ entre plantas na fileira, distribuindo-se sementes em excesso. A parcela experimental foi formada por seis fileiras de plantio, com $4 \mathrm{~m}$ de comprimento $\left(12 \mathrm{~m}^{2}\right)$. A área útil foi formada pelas quatro fileiras centrais, descontando-se $0,5 \mathrm{~m}$ em cada extremidade.

No mesmo dia da semeadura, o herbicida oxadiazon foi aplicado, em doses equivalentes a $0 \mathrm{~g}_{\text {i.a. }}$ ha $^{-1}, 200 \mathrm{~g}_{\text {i.a. }} \mathrm{ha}^{-1}, 400 \mathrm{~g}_{\text {i.a. }} \mathrm{ha}^{-1}, 600 \mathrm{~g}_{\text {i.a. }} \mathrm{ha}^{-1}$, $800 \mathrm{~g}_{\text {i.a. }} \mathrm{ha}^{-1} \mathrm{e} 1.000 \mathrm{~g}_{\text {i.a. }} \mathrm{ha}^{-1}$, com pulverizador costal pressurizado com dióxido de carbono, com pressão constante de $3,1 \mathrm{kgf} \mathrm{cm}^{-2}$ e volume de calda equivalente a $80 \mathrm{~L} \mathrm{ha}^{-1}$. No momento da aplicação, a temperatura e a umidade relativa do ar eram de $31^{\circ} \mathrm{C}$ e $86 \%$, respectivamente, sendo notada brisa leve. O solo estava úmido e sem torrões. Foi incluída uma testemunha, com controle de plantas daninhas, por meio de capina com enxada, aos 20 e 40 dias após a emergência das plantas da cultura, considerado o período crítico de competição na cultura (Matos et al. 1991). 
A emergência das plantas de feijão-caupi ocorreu no dia 29/04/2008 e o desbaste foi feito em 05/05/2008, deixando-se apenas uma planta por cova. Foram realizadas duas avaliações de tolerância do feijão-caupi ao oxadiazon, em 20/05/2008 e 19/06/2008, adotando-se, para isso, a escala de avaliação visual de Frans (1972), que varia de 1 a 9, onde 1 significa ausência de sintomas e 9 morte da planta. No dia da segunda avaliação, foi estimada a eficácia de controle de plantas daninhas, pela contagem do número de plantas daninhas por metro quadrado, utilizando-se armação vazada de madeira de $0,5 \mathrm{~m}$ de lado, lançada duas vezes na área útil de cada parcela. A parte aérea das plantas daninhas foi coletada e, em seguida, seca em estufa com circulação forçada de ar, a $65^{\circ} \mathrm{C}$, até atingir massa constante.

A colheita foi realizada em $07 / 07 / 2008$, ocasião em que cerca de $80 \%$ das vagens apresentavamse secas. Em seguida, as vagens foram debulhadas manualmente. A produtividade foi estimada corrigindo-se a umidade dos grãos para $14 \%$. Os dados foram submetidos a análises de uniformidade (teste de Lilliefors), homogeneidade dos erros de variância (teste de Cochran) e variância.

\section{RESULTADOS E DISCUSSÃO}

As plantas daninhas identificadas na área experimental estão apresentadas na Tabela 1. Cleome affinis (mussambê) é uma espécie da família Brassicaceae, de ciclo de vida anual, ereta e de porte herbáceo, com reprodução por sementes, considerada pouco frequente nas áreas agrícolas (Lorenzi 2008). O índice de importância relativa (IIR) da espécie foi o maior entre as espécies identificadas na área do experimento, antes do preparo do solo, em decorrência dos elevados valores de densidade e abundância relativas. Lopes et al. (2004) relataram que o mussambê foi uma das espécies mais importantes em área cultivada com mandioca (Manihot esculenta), com ocorrência antes do plantio e por ocasião da colheita. Entretanto, os índices de importância relativa da espécie foram pequenos $(0,09$ e 0,05$)$, nas épocas de avaliação.

Commelina benghalensis (trapoeraba) é espécie da família Commelinaceae, tem ciclo de vida perene e porte herbáceo, com reprodução tanto sexuada (sementes aéreas e subterrâneas) quanto por meio vegetativo, comum em muitas regiões agrícolas do país e com grande capacidade de interferência (Santos et al. 2004, Ronchi et al. 2007, Lorenzi 2008). A trapoeraba, semelhantemente ao mussambê, teve seus parâmetros fitossociológicos elevados, responsáveis por sua grande importância relativa na área de condução do ensaio. Esta espécie também teve importância destacada em plantio de mandioca, tanto antes quanto após o preparo do solo (Lopes et al. 2004).

Cperus rotundus (tiririca), espécie da família Cyperaceae, tem porte herbáceo, ciclo de vida perene e sua reprodução se dá por meio de sementes e brotações dos tubérculos. Quando a temperatura e a intensidade luminosa são elevadas, o crescimento das plantas é intenso e a produção de estruturas de reprodução vegetativa é aumentada, garantindo seu rápido estabelecimento nas áreas agrícolas, principalmente quando o solo é revolvido periodicamente (Jakelaitis et al. 2001).

Euphorbia heterophylla (leiteiro), família Euphorbiaceae, tem ciclo de vida anual e porte herbáceo. Sua propagação se dá por meio de sementes, liberadas da planta-mãe por meio da deiscência explosiva dos seus frutos (Lorenzi 2008). É considerada espécie de grande capacidade de interferência, devido ao fato de seu potencial de infestação ser elevado, formando reboleiras com grande número de indivíduos, e de seu mecanismo de assimilação de carbono ser do tipo $\mathrm{C}_{4}$ (Trezzi et al. 2009).

A variedade de feijão-caupi BRS Guariba foi muito tolerante às doses do oxadiazon aplicado em pré-emergência (Tabela 2). Na primeira avaliação, foi constatado que a germinação e a emergência das plântulas de feijão-caupi não foram afetadas negativamente pelo herbicida. $\mathrm{O}$ sintoma inicial

Tabela 1. Nome científico e comum, frequência relativa (FR, \%), densidade relativa (DR, \%), abundância relativa (AR, \%) e índice de importância relativa (IIR, \%) das espécies daninhas identificadas na área experimental, antes do preparo do solo (Iranduba, AM, 2008).

\begin{tabular}{lccrrr}
\hline Espécie & Nome comum & FR & DR & AR & IIR \\
\hline Cleome affinis & Mussambê & 21,5 & 44,9 & 52,7 & 119,1 \\
Commelina benghalensis & Trapoeraba & 30,3 & 37,6 & 31,1 & 99,0 \\
Cyperus rotundus & Tiririca & 28,6 & 14,9 & 13,1 & 56,6 \\
Euphorbia heterophylla & Leiteiro & 19,6 & 2,6 & 3,1 & 25,3 \\
\hline
\end{tabular}


Tabela 2. Níveis de tolerância do feijão-caupi, BRS Guariba, a doses crescentes do herbicida oxadiazon (Iranduba, AM, 2008).

\begin{tabular}{ccc}
\hline Dose $\left(\mathrm{g}_{\text {i.a. }}\right.$ ha $\left.^{-1}\right)$ & $\begin{array}{c}\text { Avaliação 1 } \\
(20 / 05 / 2008))^{1}\end{array}$ & $\begin{array}{c}\text { Avaliação 2 } \\
(17 / 06 / 2008)^{1}\end{array}$ \\
\hline 0 & 1,0 & 1,0 \\
200 & 1,2 & 1,0 \\
400 & 1,2 & 1,0 \\
600 & 1,4 & 1,0 \\
800 & 1,7 & 1,0 \\
1.000 & 1,9 & 1,0 \\
\hline
\end{tabular}

${ }^{1}$ Avaliação com base na escala visual de avaliação de Frans (1972).

mais evidente foi um leve amarelecimento das folhas cotiledonares, mais intenso no ápice da folha, em todas as doses testadas. Segundo Vidal (1997), as folhas jovens de culturas tolerantes podem apresentar clorose, que não é evidente nas demais. Outro sintoma observado foi uma leve torção das margens de algumas folhas cotiledonares. As plantas do feijão-caupi, com ou sem estes sintomas, não apresentaram nenhuma modificação do sistema radicular primário, oferecendo a mesma resistência, quando arrancadas do solo. As demais folhas não apresentaram nenhum sintoma de fitotoxicidade.

Na segunda avaliação, não foram observados sintomas visuais de fitotoxicidade significativos. Silva et al. (2003) verificaram que os herbicidas fenoxaprop-ethyl e imazamox, aplicados em pósemergência, não provocaram sintomas visuais de fitointoxicação nas plantas da variedade EPACE-10. Ishaya et al. (2008) relataram que a aplicação, em pré-emergência, da mistura dos herbicidas metolachlor e prometryn $\left(1.250+800 \mathrm{~g}_{\text {i.a. }}\right.$ ha $\left.^{-1}\right)$ não afetou, negativamente, o vigor e nem provocou sintomas visuais severos de fitotoxicidade $(2,2)$, nas plantas da variedade SAMPEA-7.

Na Figura 1, verifica-se que o número de plantas daninhas foi significativamente reduzido pela aplicação do oxadiazon. A percentagem média de redução do número de plantas daninhas, com a aplicação das doses do oxadiazon, foi de $74 \%$, correspondendo a bom nível de controle das espécies que ocorreram na área experimental. A massa seca de plantas daninhas também foi significativamente reduzida pela aplicação, em pré-emergência, do oxadiazon (Figura 2). A redução média da massa de plantas daninhas secas, obtida com as doses do oxadiazon, correspondeu a $82 \%$, o que, mais uma vez, evidenciou a excelente ação do herbicida sobre as plantas daninhas. Ishaya et al. (2008) obtiveram

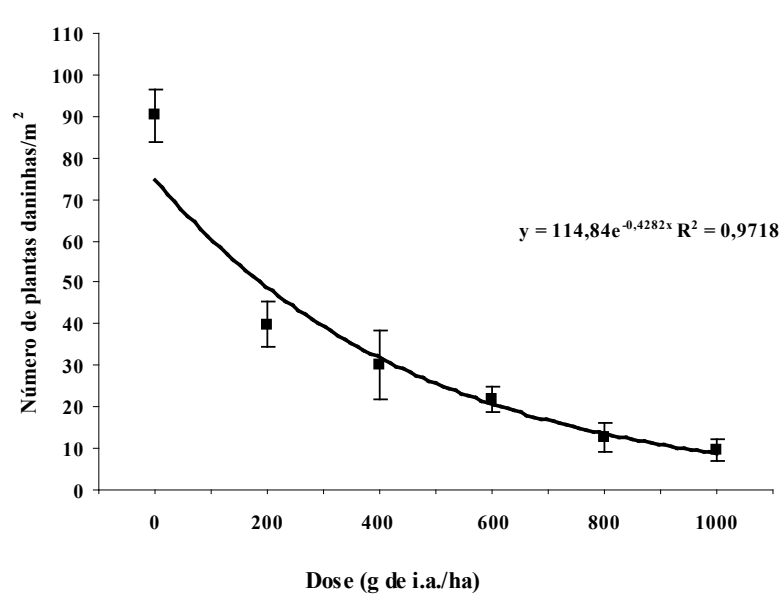

Figura 1. Densidade de plantas daninhas (plantas $\mathrm{m}^{-2}$ ), aos 55 dias após a aplicação, em pré-emergência, de doses crescentes do herbicida oxadiazon (Iranduba, AM, 2008).

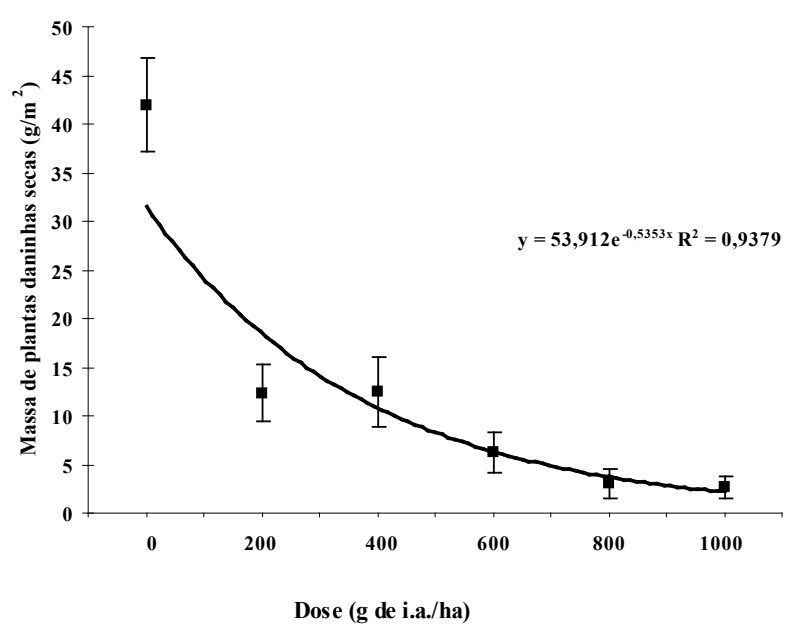

Figura 2. Massa de plantas daninhas secas $\left(\mathrm{g} \mathrm{m}^{-2}\right)$, aos 55 dias após a aplicação, em pré-emergência, de doses crescentes do herbicida oxadiazon (Iranduba, AM, 2008).

o mesmo nível de controle ( $83 \%$ ) de plantas daninhas, com aplicação, em pré-emergência, da mistura metolachlor + prometryn $\left(1.250+800 \mathrm{~g}_{\text {i.a. }}\right.$ ha $\left.^{-1}\right)$. Silva et al. (2003) obtiveram efeito semelhante sobre populações de plantas daninhas, com aplicação, em pós-emergência, dos herbicidas fenoxprop-p-ethyl e imazamox, associados ao glyphosate e ao paraquat aplicados na dessecação de plantas daninhas, em sistema plantio direto.

A produtividade de grãos de feijão-caupi foi significativamente reduzida pela interferência livre das plantas daninhas (660 $\left.\mathrm{kg} \mathrm{ha}^{-1}\right)$, evidenciando a baixa capacidade de competição da cultura, nas 


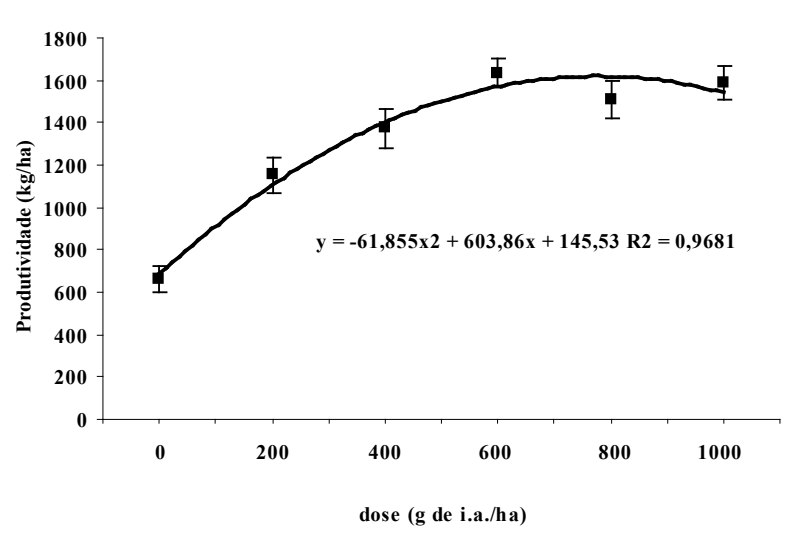

Figura 3. Produtividade de grãos de feijão-caupi, variedade BRS Guariba, obtida com aplicação de doses crescentes do herbicida oxadiazon (Iranduba, AM, 2008).

condições experimentais oferecidas. Confrontada com a maior produtividade registrada $\left(1.645 \mathrm{~kg} \mathrm{ha}^{-1}\right.$, $1.000 \mathrm{~g}_{\text {i.a. }}$ ha $^{-1}$ de oxadiazon), a interferência foi responsável por uma perda de rendimento equivalente a 59\% (Figura 3). Em outros trabalhos, foram constatadas reduções de produtividade do feijão-caupi, que variaram 29\% (Silva et al. 2003), 83\% (Ishaya et al. 2008 ) e $89 \%$ (Medeiros et al. 2008), quando não foi realizado o controle de plantas daninhas.

O nível de controle de plantas daninhas, obtido com a aplicação de doses crescentes do oxadiazon, proporcionou obtenção de excelentes produtividades de grãos da variedade BRS Guariba. A produtividade obtida com a realização de duas capinas foi de $1.561 \mathrm{~kg} \mathrm{ha}^{-1}$, evidenciando que o metabolismo das plantas não foi afetado pelo herbicida. Silva et al. (2003) e Ishaya et al. (2008) também creditaram ao controle adequado de plantas daninhas, por meio da aplicação de herbicidas, a obtenção de excelentes produtividades do feijão-caupi.

\section{CONCLUSÕES}

1. A variedade de feijão-caupi BRS Guariba foi muito tolerante ao herbicida oxadiazon, aplicado em pré-emergência.

2. O nível de controle de plantas daninhas, obtido com a aplicação do herbicida, foi considerado bom e impediu a interferência negativa das plantas daninhas sobre a cultura.

3. A dose de $600 \mathrm{~g}$ de ingrediente ativo por hectare foi suficiente para controlar as plantas daninhas e obter alta produtividade de grãos.

\section{AGRADECIMENTOS}

Ao Engenheiro Agrônomo Mário José Kokay Barroncas, supervisor do Campo Experimental do Caldeirão, e à sua equipe, pelo apoio na condução do experimento.

\section{REFERÊNCIAS}

ASSUNÇÃO, I. P. et al. Diversidade genética de Begomovirus que infectam plantas invasoras na Região Nordeste. Planta Daninha, Viçosa, v. 24, n. 2, p. 239244, 2006.

BRAUN-BLANQUET, J. Fitossociologia: bases para el studio de las comunidades vegetales. Madrid: Blume, 1979.

FRANS, R. E. Measuring plant responses. In: WILKINSON, R. E. (Ed.). Research methods in weed science. [S.1.]: Southern Weed Science Society, 1972. p. 28-41.

HARRISON JR., H. F.; FERY, R. L. Differential bentazon response in cowpea (Vigna unguiculata). Weed Technology, Lawrence, v. 10, n. 3, p. 756-758, 1993.

ISHAYA, V. B. et al. Effect of pre-emergence herbicide mixtures on cowpea (Vigna unguiculata (L.) Walp) at Samaru, in Northern Nigeria. Crop Protection, Amsterdan, v. 27, n. 7, p. 1105-1109, 2008.

JAKELAITIS, A. et al. Efeitos de sistemas de manejo sobre a população de tiririca. Planta Daninha, Viçosa, v. 21, n. 1, p. 89-95, 2001.

LOPES, C. A. et al. Comparação entre a composição florística do banco de sementes do solo e da cobertura vegetal em área cultivada com mandioca e leguminosas consorciadas. Agronomia, Seropédica, v. 28, n. 1, p. 45 $51,2004$.

LORENZI, H. Plantas daninhas do Brasil. Nova Odessa: Plantarum, 2008.

MATOS, V. P. et al. Período crítico de competição entre plantas daninhas e a cultura do caupi. Pesquisa Agropecuária Brasileira, Brasília, DF, v. 26, n. 5, p. 737 743, 1991.

MEDEIROS, V. F. L. P. et al. Períodos de interferência de plantas daninhas na cultura do feijão-caupi. In: CONGRESSO BRASILEIRO DA CIÊNCIA DAS PLANTAS DANINHAS, 26., 2008, Ouro Preto. Anais... Sete Lagoas: Sociedade Brasileira da Ciência das Plantas Daninhas: Embrapa Milho e Sorgo, 2008. 1 CD-ROM. 
MUELLER-DUMBOIS, D.; ELLEMBERG, H. Aims and methods of vegetation ecology. New York: John Willey \& Sons, 1974.

OLIVEIRA, O. M. S.; SILVA, J. F. Tolerância de variedades conservadas de feijão-caupi (Vigna unguiculata (L.) Walp) ao fomesafen. In: CONGRESSO BRASILEIRO DA CIÊNCIA DAS PLANTAS DANINHAS, 26., 2008, Ouro Preto. Anais... Sete Lagoas: Sociedade Brasileira da Ciência das Plantas Daninhas: Embrapa Milho e Sorgo, 2008. 1 CD-ROM.

RONCHI, C. P. et al. Crescimento e concentração de nutrientes no sistema radicular do cafeeiro sob competição de plantas daninhas. Planta Daninha, Viçosa, v. 25, n. 4, p. 679-687, 2007.

SANTOS, L. D. T. et al. Efeito do glyphosate sobre a morfoanatomia das folhas e do caule de Commelina diffusa e C. benghalensis. Planta Daninha, Viçosa, v. 22, n. 1, p. 101-107, 2004.
SILVA, C. M. et al. Tolerância do feijão caupi (Vigna unguiculata var. USA) a herbicidas aplicados em pré e pós-emergência. Boletim Informativo, Londrina, v. 6, n. 1, p. 6-7, 2000.

SILVA, J. B. F. et al. Controle de plantas daninhas em feijão-de-corda em sistema de semeadura direta. Planta Daninha, Viçosa, v. 21, n. 1, p. 151-157, 2003.

TREZZI, M. M. et al. Local de absorção de fomesafen como mecanismo de resistência em biótipo de Euphorbia heterophylla resistente aos inibidores de protox. Planta Daninha, Viçosa, v. 27, n. 1, p. 139-148, 2009.

VIDAL, R. A. Herbicidas: mecanismo de ação e resistência de plantas. Porto Alegre: R. A. Vidal, 1997. 